\title{
ОПРОС КАК МЕТОД ВЫЯВЛЕНИЯ И ИНТЕРПРЕТАЦИИ ОСНОВНЫХ ДИСПОЗИЦИЙ В ПОЛИТИЧЕСКОМ ДИСКУРСЕ
}

Данная статья посвящена описанию феномена объединения как ценностно-стратегической сущности в политическом дискурсе (ПД) на материале анализа опросов различных групп респондентов по ряду вопросов относительно различных форм политической коммуникации.

Цель данной работы - выявить и охарактеризовать диспозиции адресатов на основе анализа и обобщения ответов на вопросы, реферируемые к теме «Политика». Объект исследования - диспозиции субъектов коммуникации; предмет - их вербализация. Новизна подхода заключается в применении метода опроса как эффективного средства вычленения и характеристики основных установок в политической субъект-субъектной коммуникации; в интерпретации феномена объединения. Результаты исследования показали наличие в целом четырех типов установок - положительной, отрицательной, нейтральной, амбивалентной, характеризующих адресатов vs адресантов. Отмечается, что амбивалентное отношение имеет противоречивую актуализацию, одновременно учитывающую позитивную и негативную диспозиции. Доказано, что в целом позитивная и негативная диспозиции в дискурсе респондентов актуализируют соответствующие стороны синергетического процесса как дина- мического явления преодоления дисбаланса. Выявлено, что нейтральная диспозиция выражена противоречиво подобно амбивалентной диспозиции. При этом различаются эксплицитная («нейтрально») и имплицитная нейтральность. В большинстве случаев позиционируемая нейтральность непоследовательно реферирует к доводам, в реальности обосновывающим позитивное и негативное отношение.

Таким образом, доказано, что дискурс респондентов представляет собой ответные реакции на поставленные вопросы в диалогическом режиме, характеризуя обратную связь как адресантно vs адресатную коммуникацию и не представляет собой повсеместное выражение результата воздействия со стороны адресантов (агентов) политического дискурса; он формируется при актуализации процессов дифференциации и интеграции, образующих феномен объединения, выраженный в единстве ценностных (общечеловеческих, общекультурных, личностных) смыслов и стратегической (диспозициональной) ориентации.

Ключевые слова: политический дискурс; дискурс респондентов; диспозиция; адресантно-адресатная коммуникация; диалогичность; феномен объединения.

\section{E. S. Grushevskaja}

\section{SURVEY AS A METHOD OF IDENTIFICATION AND INTERPRETATION OF MAJOR DISPOSITIONS IN POLITICAL DISCOURSE}

This article describes the phenomenon of unification as a value-strategic entity in political discourse based on the analysis of surveys of different groups of respondents on a number of issues regarding various forms of political communication.

The purpose of this work is to identify and characterize the dispositions of addressees on the basis of the analysis and synthesis of answers to the questions referenced to the topic "Politics". The object of study is the dispositions of the subjects of communication; the subject is their verbalization. The novelty of the approach lies in the application of the polling method as an effective means of isolating and characterizing the basic attitudes in the political subject-subject communication; in the interpretation of the phenomenon of association. The results of the study showed the presence of four types of installations in general - positive, negative, neutral, ambivalent, characterizing the recipients vs addressees. It is noted that an ambivalent attitude has a controversial update, at the same time taking into account the positive and negative dispositions. It is proved that, on the whole, positive and negative dispositions in the discourse of respondents actualize the relevant sides of the synergistic process as a dynamic phenomenon of overcoming imbalance. It is revealed that the neutral disposition is expressed in a contradictory way like an ambivalent disposition. At the same time, explicit ("neutral") and implicit neutrality differ. In most cases, positioned neutrality inconsistently reviews the arguments that, in reality, justify a positive and negative attitude.

Thus, it is proved that the discourse of respondents is a response to the questions posed in the dialogical mode, characterizing the feedback as addresser vs addressee communication and does not represent the ubiquitous expression of the result of influence from the addressees (agents) of political discourse; it is formed during the actualization of the processes of differentiation and integration, forming the phenomenon of unification, expressed in the unity of value-based (universal, general cultural, personal) meanings and strategic (dispositional) orientation.

Key words: political discourse; discourse of respondents; disposition; addresser-addressee communication; dialogue; unification phenomenon. 
В многомерном исследовании политического дискурса особое место традиционно отводится изучению его стратегических и ценностных характеристик, исходя из конечной цели убеждения, с точки зрения теории воздействия [см. к примеру 1-8]. Актуальность исследуемой проблемы обусловлена необходимостью перспективного изучения категории адресатности в субъект-субъектной коммуникации, исходя из нового, эмпирического подхода, нацеленного на выявление и интерпретацию конкретных диспозиций, характеризующих тип адресата. Новизна подхода в данной работе заключается в прояснении традиционного подхода в альтернативно-комплементарном ракурсе, заключающемся в привлечении дополнительного понятия «ценностно-стратегический феномен», формирующего типы диспозиций, выявленных в дискурсе респондентов, содержащих когнитивные и психологические факторы. Таким образом, данная статья посвящена описанию феномена объединения как ценностно-стратегической сущности в политическом дискурсе (ПД) на материале анализа опросов различных групп респондентов по ряду вопросов относительно различных форм политической коммуникации. Основные вопросы, формирующие позицию адресатов относительно политического дискурса, следующие:

1) Внушаемы ли Вы? Обобщите свои наблюдения относительно функции воздействия. Какие индивидуумы наиболее внушаемы?

2) Как Вы относитесь к политике (положительно/отрицательно)? Объясните свое отношение по принципу «польза/вред».

3) Ходите ли Вы на выборы? Да/нет. Почему?

4) Как Вы относитесь к митингам и акциям протеста? Участвуете ли Вы в них? Да/нет. Почему?

5) Как Вы относитесь к политическим дебатам? Смотрите ли теледебаты?

6) Какие чувства и эмоции Вы испытываете при виде политической рекламы?

Ответы на первый вопрос выявили неоднозначное отношение респондентов к внушению, базовой составляющей функции воздействия. Дискурс респондентов в подавляющем большинстве характеризуется отрицанием фракта внушения, соответственно воздействия. Далее следует интерпретация ответов на вопросы о ПД, содержащих информацию от общего к частному. Так, второй вопрос ориентирован на выявление отношения к политической коммуникации в целом. Ответы адресатов представляют широкий спектр выражения мнения, позиции. Далее следуют вопросы частного характера относительно конкретных форм политического дискурса - выборы, митинги, акции протеста, политические (теле)дебаты, политическая реклама. Ответы на перечисленные вопросы формируют определенные классы субъектов политической коммуникации. При этом речь идет не только о возможности выявления типологии адресатов, но и их характеристике в качестве адресантов. Данный феномен указывает на цельнооформленность ПД как самоорганизующейся системы, в которой есть место как хаосу, так и порядку. И в этом процессе особое место занимают функции (само)организации, (само)регуляции как субъектов политической коммуникации, так и ее структуры как системы. При этом базовым механизмом представляется функция (само)идентификации относительно координации собственной установки и диспозиций других субъектов коммуникации. По результатам исследования установлено в целом четыре типа диспозиций - негативная, позитивная, нейтральная, амбивалентная. Рассмотрим их репрезентацию в дискурсе респондентов относительно обсуждаемых вопросов.

Ответы на второй вопрос - Отношение к политике - в дискурсе респондентов выражены в различных диспозициях. Отрицание происходит на базе референций к следующим факторам, которые явлены как доводы (аргументы) - объективного (политика как система, критерий истины) и субъективного - (эффективность / неэффективность (бессмысленность, бесполезность, вред); компетентность / некомпетентность адресантов / адресатов; эмоциональность (пессимизм, стресс) адресатов) характера. Нейтральность выражается на основе следующих факторов (доводов, оснований): объективные (политика как необходимая система; адресат как внешний наблюдатель, направленный на объективность) и субъективные (адресат как внешний наблюдатель с учетом информационной ориентированности; компетентность / некомпетентность адресатов; недостаточность вовлеченности; ссрера интересов; ситуативность; формально нейтральное отношение, имплицитно выражающее неприятие). Позитивная установка акцентируется собственно компетентностью адресатов относительно высказываемого, выраженного в позитивной тональности, переданной соответствующей лексикой. Объективные доводы, основания: политика как необходимая система, составляющая государства; указание на абстрактную сущность; указание на конкретную функцию (к примеру, внешнеполитическая); указание на функцию взаимодействия (ср. с функцией воздействия). Субъективные доводы, основания: дискурсивная экспликация посредством маркера тональности; референция на ценностные установки адресантов (к примеру, политики, ориентированные на благо общества); указание на необходимые характеристики собственно политики (правильная, грамотная, разумная); указание на необходимые характеристики адресатов ПД (политическая грамотность, сознательность, ангажированность); указание на формальную позитивность с допущением, характеризующую невовлеченность («отписка»); указание на неформальную позитивность адресатов (оптимистов), в качестве адресантов, транслирующих позитивные установки. Амбивалентное отношение выражает диалектическое единство положительных и отрицательных сторон ПД, указанных нами в позициях субъективных и объективных факторов. В нем диффференцированы обе стороны (польза/вред) в виде перечисления "плюсов» и «минусов», как в отношении системы и структуры, так и субъектов в полити- 
ческой коммуникации. Данный тип выражения отношения характеризует тип личности, ориентированный на целостный подход с неформальной / формальной (отписка) установкой адресата в качестве адресанта политической коммуникации.

Дискурс респондентов относительно выборов (ответы на третий вопрос) изучается в диспозициях - позитивная, негативная, амбивалентная. Позитивное отношение к выборам явлено в следующих общих ценностных смыслах: «гражданский долг», «патриот», «обязанность», «ответственность», «волеизъявление», «выражение выбора», реализация которых контекстуально обусловлена, т.е. реферирует к условиям и понятиям различного рода - «возможность», «достойный кандидат». В контексте обозначенных смыслов актуализируется стратегия объединения, явленная в позиционировании личности в качестве части целого: «не остаться в стороне», «внести свой вклад», «мое решение влияет на...», «голос каждого», «участие в управлении государством», "делаю то малое, что могу". В данном ключе выявляются активные адресаты, рассматриваемые нами в качестве адресантов, т.е. неформальных граждан, оптимистов. При реферировании к деонтической сфрере, к формальной актуализации ценностных смыслов, реализуется тип формальный тип гражданина. Негативное отношение формируется на основе предвзятого мнения, выраженного на неуверенности, отсутствии веры со стороны адресата. Отрицательная диспозиция выявляет следующие понятия в виде контраргументов (и соответствующих следствий), идущие вразрез с ценностями позитивной диспозиции: “предопределенность», «бессмысленность» (нечестность выборов», “отстраненность) («абсентеизм»); «отсутствие интереса к теме», «личная некомпетентность», “наличие / отсутствие кандидатуры», «аргумент к возрасту», «ссылка на неудачный опыт». Соответственно формируется ситуация размежевания, противопоставленная феномену объединения. Амбивалентное отношение, в свою очередь, имеет противоречивую актуализацию, одновременно учитывающую позитивную и негативную диспозиции. Оно представляет когнитивную систему субъекта (адресата / адресанта) как пространство полимодальной актуализации знаний, мнений, верований

Дискурс респондентов относительно митингов и акций протеста (ответы на четвертый вопрос) сформировался в следующих установках: положительная, отрицательная, амбивалентная, нейтральная. В позитивной диспозиции характеризуются две категории граждан с точки зрения деятельности - участвующие и не участвующие (поддерживающие - «уважение кпротестующим») в митингах и акциях протеста. Таким образом, позитивное отношение к данным формам ПД явлено в следующих общих ценностных смыслах и понятиях: «интерес» («любопытство»), «осознанная необходимость», «выражение недовольства», «возможность донести свою позицию», «тематическая обусловленность», «содействие решению проблем», «справедливость». В дискурсе респон- дентов эксплицированы следующие необходимые субъективные и объективные требования («законность», «мирная атмосфрера», «анонимность», "тематическая обусловленность») и ограничения к названным формам ПД: “отсутствие подобных форм в городе (стране)», “отсутствие времени / здоровья / мотива). В данной диспозиции неучастие в митингах и акциях протеста актуализирует аргумент «бесполезность» («бессмысленность») адресата "скептика-пессимиста". В обратной активной позиции адресат фигурирует в роли адресанта ПД. Политический дискурс явлен как динамическая система, преодолевающая догмат институциональности субъект-субъектных отношений. Анализируемые формы политической коммуникации, как и дискурс респондентов, их интерпретирующий, суть актуализация естественного процесса взаимодействия собственно институционального и персонального типов дискурса, указывающая на равную значимость условно называемых ролей агентов и клиентов. В позитивном отношении актуальны смыслы и ассоциативные образы, способствующие координации действий в адресантно(vs)адресатной коммуникации институционально-персонального (группового) порядка: «современное взаимодействие», «противовес», «нововведения», «исправление ошибок», «контакт».

Отрицательная диспозиция к митингам и акциям протеста может быть выражена односложно, а также с представлением аргументов: «отсутствие интереса», «бессмысленность», «бесполезность», «нецелесообразность». При этом некоторые понятия («опасность), «конфликтность» и др.), актуальные в положительной диспозиции в качестве ограничительных условий, явлены в качестве аргументов «против» при негативной диспозиции. В основе неприятия фиигурируют негативные смыслы и ассоциативные образы: «толпа», «опасность», «страх», «дискомфорт», «конфликт», «насилие», «раздор», «нестабильность», «революция», «полиция», «разгром», «огонь», «драка», «кутузка», «2-ой Майдан», «агрессия», «дисбаланс». Коннотативно негативно маркировано понятие «толпа» как источник хаоса во всех смыслах. Толпа ( «стадо») есть негативный субъект анализируемых форм ПД формируемый из клиентов агентами политической коммуникации. Основной стратегией при этом явлена стратегия объединения.

В целом позитивная и негативная диспозиции в дискурсе респондентов актуализируют соответствующие стороны синергетического процесса как динамического явления преодоления дисбаланса. Данный процесс цельно представлен в амбивалентной диспозиции. При этом в ряду отрицательных смыслов отмечаем аналогичные понятия, аргументы «против»: «опасность», «страх», (насилие», “дебоширство»; а в ряду положительных аргументов «за»: «возможность выразить мнение», «быть услышанными», «претензии», «недовольство» (для клиентов ПД); «обоснованность», «польза», «справедливость», «эфффективность» (собственно для ПД). Невы- 
полнение положительных условий способствует формальной («показуха») актуализации данных форм ПД. Интроспекция при интерпретации субъектов коммуникации выявляет тип субъекта «не активно протестующий».

Нейтральная диспозиция выражена противоречиво подобно амбивалентной диспозиции. При этом различаем эксплицитную («нейтрально») и имплицитную нейтральность. В большинстве случаев позиционируемая нейтральность непоследовательно реферирует к доводам, в реальности обосновывающим позитивное и негативное отношение. Значимым компонентом релевантной актуализации митингов и акций протеста объявляется тематическая составляющая. Она фигурирует в качестве важного средства переключения внимания, а также значимого фактора объединения групп лиц в таких формах ПД, как митинги и акции протеста. При этом важна степень мотивации, степень "возмущения чем-либо» относительно насущных проблем в различных сферах повседневности (к примеру, сортировка мусора, защита животных, тарифы ЖКХ, пенсионное законодательство и др.).

Дискурс респондентов по отношению к теледебатам (ответы на пятый вопрос) характеризуется в следующих направлениях: нейтральное, негативное, позитивное, амбивалентное.

Нейтральное отношение выражено преимущественно односложно. При эксплицировании данной диспозиции, референции к когнитивной составляющей колеблются от незнания к выражению собственного мнения. Отрицательное отношение также может быть актуализировано односложно с указанием как на знание, так и незнание предмета обсуждения, и объективные факторы. С другой стороны, объективный фактор, к примеру, “отсутствие телевизора» может указывать на субъективную диспозицию респондента с позиционированием его как адресата «теленезависимого». Негативное отношение при этом выражено на основе эмотивной лексики, характеризующей эмоциональное неприятие («бесят», «нервируют», (раздражает», «испанский стыд»). Когнитивная составляющая отрицательной диспозиции выражена в следующих понятиях, реферирующих к смыслу: «бессмысленность», «необъективность», «несерьезность», «бесполезность», «неформат», «отсутствие интереса».

Отсутствие интереса явлено как базовый аргумент к неприятию в целом. Эмоциональное неприятие при имплицитно выраженном отсутствии интереса может обосновываться представлением альтернативы, в некоторых случаях и шуточно. С одной стороны, рациональное отрицание при отсутствии интереса реферирует к аргументам «отсутствие новизны», «формализм», с другой стороны, негативная диспозиция раскрывает неприятие стилистики и тональности теледебатов, а также фракт игнорирования темы как дискурсообразующему компонента.

Таким образом, интерпретация дискурса респондентов относительно теледебатов позволяет выявить противоречие с точки зрения реализа- ции их формы и содержания: с одной стороны теледебаты позиционируются как формальный феномен, с другой стороны, выявляется факт невыполнения формальных (и содержательных) требований. Актуализация фактора «интерес» / "отсутствие интереса» соотносится также с тематической составляющей.

Положительное отношение выражено без аргументации, в некоторых случаях эмоционально в различной степени («крайне», «люблю», «обожаю»). Как и в случае отрицательной диспозиции, позитивное отношение обосновывается аргументом «интерес) неформально («очень сильный интерес», “несормальная обстановка», «достойный кандидат», «выявление компетентности») и формально. Неформальное отношение реферирует собственно к когнитивному (информационному) и ценностному компонентам. При этом в дискурсе респондентов особое значение приобретает актуализация формально-процессуального характера дебатов, с указанием на возможность приобретения компетентности с точки зрения полезности.

Амбивалентное отношение содержит в себе элементы позитивного и негативного отношения, т.е. выражает противоречивую диспозицию, характеризующую противоположное отношение к двум вопросам, включая такие аргументы как «ситуативность», «ограничения», «интерес». Специфика негативного отношения как составляющего амбивалентной диспозиции выражена в аргументе (мотиве) «антиэстетическое удовольствие», который явлен такими лексическими единицами, как «глумление», «ирония», «недоверие», «глупость кандидатов». Мотив «антиэстетическое удовольствие» актуализирует развлекательную функцию посредством ЛЕ (шоу), «цирк», «клоунада», "сборище клоунов», «веселье». Амбивалентное отношение являет собой диспозицию, в наибольшей степени направленную на вовлеченность в субъект-субъектную коммуникацию. При этом актуальны мотивы «включенность» в реальный процесс политической коммуникации самих клиентов ПД, а также «призыв к объективности», которые основаны, прежде всего, на значимость когнитивной составляющей.

Отношение к политической рекламе (ответы на шестой вопрос) в дискурсе респондентов выстроилось по следующим направлениям - негативное, нейтральное, амбивалентное, позитивное

Негативное отношение превалирует в дискурсе различных категорий респондентов. Оно реализуется односложно (номинативно и предикативно) в дифференцированном диапазоне чувств и эмоций: «рвотные позывы», «бесит», «отвращение» («ближе к отвращению»), «неприязнь», «негодование», «раздражение», «ужасно», “недоверие», «неинтересно», «смех», «ирония», «бал-маскарад», “умиление», «испанский стыд». Объектом интерпретации явлена сама политическая реклама. Она характеризуется следующими ЛЕ с негативной коннотацией: «натянутая», «приставучая», «некреативная», «некачественная», «вычурная». Негативная диспозиция реферирует 
к когнитивной составляющей («игнорирую», «ненужная для меня информация»), а также к критерию «истина / ложь» («ложь), «обман», «честные лица» (ирон.), «благородные устремления» (ирон.), «завираются»). Дискурс респондентов при этом фиксирует актуализацию комиссивов, грамматически вербализуемых в будущем и прошедшем временах («обещания ... в итоге не выполнят»; «невыполненные обещания»). Негативная диспозиция строится посредством указания на отсутствие следующих понятий: «эффективность», «польза», «уместность».

Анализ дискурса респондентов значим возможностью исследования обратной связи, характеризуемой диалогичностью. Она выражается косвенными речевыми актами, репликами («Хочется выключить», «Переключите рекламу, плз» «Закатывание глаз считается?». Негативная диспозиция дополняется прескрипциями, указывая на альтернативу.

Нейтральное отношение выражено чаще всего односложно и развернуто («Нейтрально», «Равнодушие», «Ничего не испытываю», «Абсолютно никаких эмоций не испытываю» и др.). Оно формируется исходя из принципа «от общего к частному», т. е. политическая реклама рассматривается как вид рекламы. При этом отмечаем точку зрения, при которой данный принцип нерелевантен. В качестве аргументов нейтральной диспозиции актуализируются доводы «интересы», «право», «политическая позиция».

Амбивалентная диспозиция в дискурсах респондентов закономерно реализует контрадикторные (смешанные) чувства и эмоции (смех и раздражение), а также наличие элементов нейтральности

Положительное отношение выражено односложно («Интерес», «Заинтересованность») и развернуто. Дискурс респондентов актуализирует психологическую («приятно видеть лица и слышать голос») и когнитивную составляющие («можно узнать, что предлагает избиратель»). Позитивная диспозиция реферирует к конкретным условиям, соотносимым к собственно рекламе («реклама грамотная») и к адресантам («реклама достойных политиков») ПД. Подобно негативной диспозиции при позитивном отношении актуальны аргументы «польза», «эффективность».

Особого внимания заслуживают дискурсы респондентов, в которых в разной степени представлен факт наличия феномена внушения и воздействия, релевантного в различных диспозициях. В целом, значимым выводом представляется указание на дискурсообразующий фактор хронотопа при интерпретации стратегии воздействия как объекта исследования. При этом констатируется факт неэффективности стратегии воздействия в современных условиях политической коммуникации

Таким образом, анализ эмпирического материала позволил сделать следующие выводы:

1. Дискурс респондентов представляет собой ответные реакции на поставленные вопросы в диалогическом режиме, характеризуя обратную связь как адресантно vs адресатную коммуникацию.

2. Наличие обратной связи позволяет рассматривать отдельного субъекта (персонального клиента) политической коммуникации как несормального конкретного адресата, мнение которого суть составляющая матрицы референциальных отношений политического дискурса.

3. Дискурс респондентов при этом не есть тотальное выражение результата воздействия со стороны адресантов (агентов) политического дискурса; он формируется при актуализации процессов дифференциации и интеграции, образующих феномен объединения, выраженный в единстве ценностных (общечеловеческих, общекультурных, личностных) смыслов и стратегической (диспозициональной) ориентации.

\section{Литература}

1. Баранов А. Н., Паршин П. Б. Языковые механизмы вариативной интерпретации действительности как средство воздействия на сознание // Роль языка в средствах массовой коммуникации. М.: ИНИОН, 1986. С.100-143.

2. Блакар Р. М. Язык как инструмент социальной власти // Язык и моделирование социального взаимодействия. М.: Наука, 1987. С.88-125.

3. Иссерс О. . Речевое воздействие: учебное пособие. М.: Флинта: Наука, 2011. 224 с.

4. Карасик В. И. Языковая спираль: ценности, знаки, мотивы. Волгоград: Парадигма, 2015. 432 с

5. Романов А. А. Политическая лингвистика. Функциональный подход. Москва - Тверь: Ин-т языкознания РАН, ТВГУ, 2002. $191 \mathrm{C.}$.

6. Стернин И. А. Введение в речевое воздействие. Воронеж: «Истоки», 2012. 178 с.

7. Чудинов А. П. Политическая лингвистика: учеб. пособие. 4-е изд. М.: Флинта: Наука, 2012. 256 с.

8. Шейгал Е. И. Семиотика политического дискурса. М.; Волгоград: Перемена, 2000. 367 с.

\section{References}

1. Baranov A. N., Parshin P. B. Yazyikovyie mehanizmyi variativnoy interpretatsii deystvitelnosti kak sredstvo vozdeystviya na soznanie (Linguistic Mechanisms of Variative Interpretation of Reality as a Means of Influencing the Consciousness) // Rol yazyika v sredstvah massovoy kommunikatsii. Moscow: INION, 1986. P.100-143. (In Russian)

2. Blakar R. M. Yazyik kak instrument sotsialnoy vlasti (Language as a Tool of Social Power) // Yazyik i modelirovanie sotsialnogo vzaimodeystviya. Moscow: Nauka, 1987. P.88-125. (In Russian)

3. Issers O. S. Rechevoe vozdeystvie: uchebnoe posobie (Speech Impact: Study Guide). Moscow: Flinta: Nauka, 2011 224 p. (In Russian) 
4. Karasik V. I. Yazyikovaya spiral: tsennosti, znaki, motivyi (The Language Spiral; Values, Signs, Motives). Volgograd: Paradigma, 2015. 432 p. (In Russian)

5. Romanov A. A. Politicheskaya lingvistika. Funktsionalnyiy podhod (Political Linguistics. Functional Approach). MoscowTver: IYa RAS publ., TvSU publ, 2002. 191 p. (In Russian)

6. Sternin I. A. Vvedenie $\vee$ rechevoe vozdeystvie. (Introduction to Speech Exposure). Voronezh: Istoki, 2012. 178 p. (In Russian)

7. Chudinov A. P. Politicheskaya lingvistika (Political Linguistics) Moscow: Flinta: Nauka, 2012. 256 p. (In Russian)

8. Sheygal E. I. Semiotika politicheskogo diskursa (Semiotics of Political Discourse). Moscow; Volgograd: Peremena, 2000. 367 p. (In Russian)

Сведения об авторе

Грушевская Елена Сергеевна - кандидат филологических наук, доцент кафедры английской филологии Кубанского государственного университета (Краснодар) / kff-kubsu@уandex.ru

Information about the author

Grushevskaya Elena-PhD in Philological Sciences, Associate Professor, Chair of English Philology, Kuban State University (Krasnodar) / kff-kubsu@yandex.ru 